\title{
Unilateral retinoblastoma: new intraocular tumours after treatment
}

\author{
David H Abramson, Lisa S Gamell, Robert M Ellsworth, Erik F Kruger, Camille A Servodidio,
} Liebert Turner, David Sussman

\begin{abstract}
A retrospective chart review of 427 eyes diagnosed with unilateral retinoblastoma was performed to determine which eyes, which patients, and when new intraocular tumours would develop after treatment. Mean follow up was $8 \cdot 16$ years. Twenty five (6\%) of 427 unilateral retinoblastoma patients developed new intraocular tumours after treatment. Five (1\%) unilateral patients who were previously treated with enucleation developed new tumours (in the fellow eye). Fifteen (24\%) unilateral patients who were previously treated with external beam radiation developed new tumours (equally in either eye). New tumours did not develop in the macula of either eye. The relative risk of developing new intraocular tumours after treatment was $16 \%$ in patients diagnosed before 1 year old and $2 \cdot 2 \%$ for patients diagnosed after 1 year old $(\mathbf{p}<0 \cdot 001)$. The mean time to onset for the development of new tumours after treatment was 0.74 years; no new tumours appeared after 7.5 years of age. Those patients who are diagnosed with unilateral retinoblastoma in the first 6 months of life and have a family history of the disease are at greatest risk of developing new intraocular tumours.
\end{abstract}

(Brf Ophthalmol 1994; 78: 698-701)

Retinoblastoma is the most common primary, malignant intraocular tumour of childhood with an incidence of $1: 17000$ to $1: 34000$ new births. ${ }^{12}$ One third of the cases are bilateral and two thirds unilateral, although some unilaterally diagnosed cases go on to develop tumours in the fellow eye and become bilateral. ${ }^{3}$ Children with unilateral retinoblastoma are usually diagnosed at a later age than bilateral retinoblastoma. ${ }^{4}$ Unilateral retinoblastoma most commonly presents with advanced intraocular disease ${ }^{5}$ and is treated with enucleation. ${ }^{6}$ Survival rates of over $90 \%$ are now widely reported for unilaterally affected patients treated with simple enucleation. ${ }^{7}$

In recent years it has been recognised that some cases of unilateral retinoblastoma can be managed without primary enucleation. The diagnosis may be made at an earlier age ${ }^{8}$ and stage ${ }^{9}$ in children with a family history of retinoblastoma, when small retinoblastomas affect the macula of one eye, causing strabismus, or when the eye is examined for other reasons in the first few months of life. Modalities used for primary therapy include external beam radiotherapy, localised radioactive applicators, cryotherapy, photocoagulation, and, more recently, systemic chemotherapy. ${ }^{111}$
Although such 'conservative' approaches to managing unilateral retinoblastoma have enabled physicians to salvage eyes and vision without sacrificing survival, it has been emphasised that the decision to manage unilateral retinoblastoma without enucleation requires careful analysis of the risks and benefits of such an approach. ${ }^{8}$

When bilateral retinoblastoma is treated without enucleation it is not uncommon for two events to occur. The first is failure of the initial treatment to control the tumour that was treated. This occurs in $24-50 \%$ of cases. ${ }^{2}$ The second is the subsequent development of new, intraocular tumour foci. This proclivity to develop new tumours is related to the age at which the children are treated, and not to treatment modality. ${ }^{12}$ When treated within the first 3 months of life, $58 \%$ of children will go on to develop such tumours. The chance of developing new tumours diminishes when children are treated at an older age and by 33 months of age is less than $1 \%$. All tumours that develop are at or anterior to the equator and never found in a previously normal macula. ${ }^{12}$

No such information, however, exists in the literature for children with unilateral retinoblastoma. It would be useful to have a means of predicting when and which patients with unilateral disease are most likely to develop new tumours after treatment. Do they develop new tumours in the same, fellow, or both eyes after treatment? Information regarding the location and time course for the development of the new intraocular tumours after treatment may ultimately allow us to design a more precise patient follow up scheme.

\section{Materials and methods}

A retrospective analysis of 770 cases of clinically diagnosed unilateral retinoblastoma was carried out utilising the records of the Ophthalmic Oncology Center of The New York Hospital Cornell Medical Center. Included in this collection were cases diagnosed between 1914 and 1992. Excluded from the study were 79 cases with insufficient follow up, 185 cases seen for consultation only and treated elsewhere, 67 cases involving death secondary to metastases (because this precluded our ability to follow the eye(s) for the subsequent development of new tumours), and 12 cases of 'retinoma'. The mean follow up was $8 \cdot 16$ years.

Children included in this study were initially treated with one or more of the following: enucleation, external beam radiation, cryotherapy, photocoagulation, systemic chemotherapy - either in single or combination 


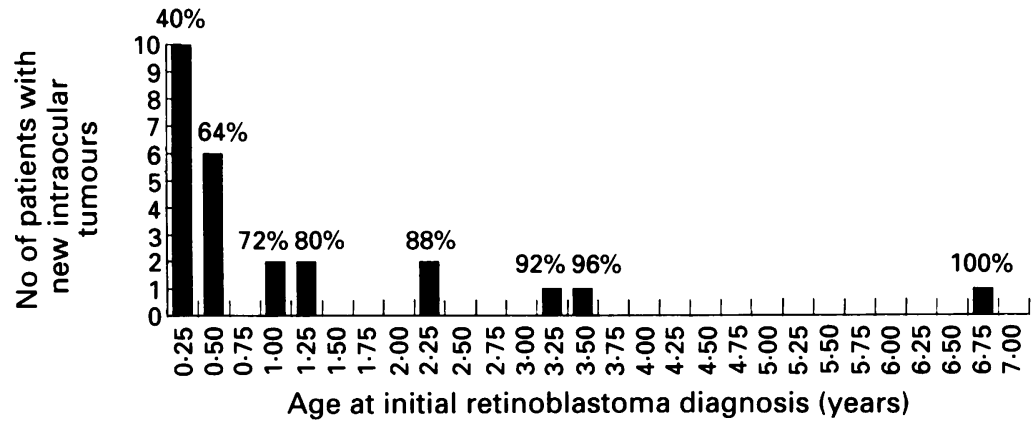

Figure 1 The number of patients developing new tumours when initially diagnosed at a particular age and the percentage of all new tumours diagnosed during a given age range.

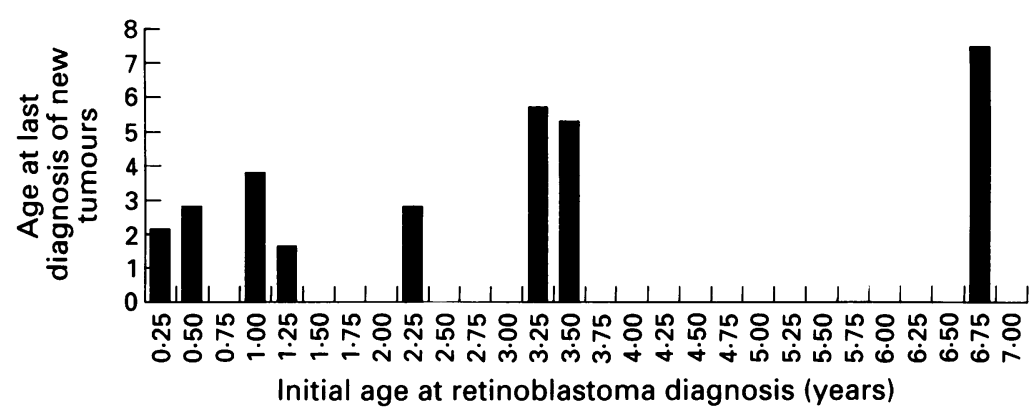

Figure 2 Plot demonstrating the last age at last diagnosis of new tumours for patients initially diagnosed with retinoblastoma at a certain age.

therapies. Tumours that regrew after primary treatment was initiated were considered to be recurrences and not new tumours. Likewise, vitreous seed implantation growths were not classified as new tumours. All other tumours first observed after primary treatment was initiated were considered to be new tumours.

Data were coded into age at diagnosis, sex, Reese-Ellsworth group at diagnosis, laterality and intraocular location of tumour, family history, initial treatment modality, follow up, subsequent treatment modalities, laterality and intraocular location of new tumours, and time course for the development of new tumours.

\section{Results}

Four hundred and twenty seven patients with unilateral retinoblastoma diagnosed between 1914 and 1992 were included in the study. The mean age of diagnosis was 2.0 years with a range from 0.01 to 12.9 years. Disease was initially diagnosed in the right eye in $217(51 \%)$ patients.
Male patients comprised $218(51 \%)$ members of the group. A total of $26(6 \%)$ patients had a family history of retinoblastoma. Distribution of initial treatment modalities included 338 patients treated with enucleation, three with cryotherapy, three with photocoagulation, and 62 with radiation. The remaining 20 patients were initially treated with more than one modality.

\section{NEW TUMOURS}

Of the 427 eyes selected for the study, 25 (6\%) went on to develop new intraocular tumours (Fig 1). The mean age at diagnosis in this group was 1.0 years with a range of 0.01 to 6.75 years. The risk of developing a new tumour if initially diagnosed before 1 year of age was $16 \%$; the risk after 1 year of age was only $2 \cdot 2 \%$. The highest risk for developing new tumours was among those patients initially diagnosed with disease in the first 3 months of life and was $33 \%$.

The age at onset of new tumours ranged from 0.25 to 7.50 years with a mean of 1.8 years. The mean time course for the development of new tumours was 0.74 years after initial diagnosis and treatment, with a range from 0.08 to 2.83 years. No new tumours were diagnosed after the age of $7 \cdot 50$ years. Figure 2 represents the peak age at last diagnosis of new tumours in patients initially diagnosed at a certain age.

Table 1 demonstrates the development of new tumour foci after various modes of treatment. The overall age of diagnosis is 1 year earlier for those who develop new tumours $(1 \cdot 0)$ when compared with those who do not develop new tumour foci $(2 \cdot 0)$. In addition, the mean age at diagnosis for those who were enucleated and developed new tumours is earlier as well, by 1.40 years.

\section{FAMILY HISTORY}

Among the 26 patients with a family history of retinoblastoma, nine $(35 \%)$ went on to develop new intraocular tumours. The mean age at diagnosis was 0.2 years with a range from 0.01 to 0.5 years. The age at diagnosis of new tumours ranged from 0.25 years to 0.75 years with a mean of 0.6 years. The time interval for the onset of new tumours was 0.25 years to 0.71 years with a mean of 0.4 years. Among those patients with a family history, $100 \%$ who went on to develop new intraocular tumours were initially diagnosed with retinoblastoma before 6 months of age and did not develop any new tumours after $2 \cdot 08$ years

Table 1 Initial treatment modality and new tumour development

\begin{tabular}{|c|c|c|c|c|c|c|c|c|}
\hline Modality ${ }^{\star}$ & $\begin{array}{l}\text { No of } \\
\text { patients }\end{array}$ & $\begin{array}{l}\text { Age at } \\
\text { diagnosis }\end{array}$ & $\begin{array}{l}\text { No of new } \\
\text { tumours }(\%)\end{array}$ & $\begin{array}{l}\text { Family } \\
\text { history }(\%)\end{array}$ & $\begin{array}{l}\text { Age at } \\
\text { diagnosis of } \\
\text { new tumour }\end{array}$ & $\begin{array}{l}\text { Age at new } \\
\text { tumour }\end{array}$ & Interval & $\begin{array}{l}\text { Last new } \\
\text { tumour }\end{array}$ \\
\hline Overall & 427 & $2 \cdot 0$ & $25(6)$ & $9(36)$ & $1 \cdot 0$ & 1.9 & 0.7 & $7 \cdot 5$ \\
\hline Enuc & 338 & $2 \cdot 2$ & $5(1)$ & $1(20)$ & 0.8 & 1.7 & 0.9 & $2 \cdot 58$ \\
\hline EBR & 62 & $1 \cdot 2$ & $15(24)$ & $4(23)$ & $1 \cdot 2$ & $2 \cdot 1$ & 0.8 & $7 \cdot 50$ \\
\hline Cryo & 3 & 1.8 & 0 & & 12 & 21 & 00 & \\
\hline Photo & 3 & $0 \cdot 2$ & $2(67)$ & $2(67)$ & 0.07 & $0 \cdot 4$ & $0 \cdot 3$ & $1 \cdot 3$ \\
\hline En/Chemo & 11 & 1.5 & 0 & & & & & \\
\hline $\mathrm{En} / \mathrm{EBR} / \mathrm{Ch}$ & 2 & $5 \cdot 0$ & 0 & & & & & \\
\hline $\mathrm{EBR} / \mathrm{Ch}$ & 3 & 1.5 & 0 & & & & & \\
\hline EBR/Cryo & 2 & $1 \cdot 3$ & $2(100)$ & $1(50)$ & $1 \cdot 3$ & 1.6 & 0.3 & $2 \cdot 8$ \\
\hline Photo/Cryo & 1 & 0.25 & $1(100)$ & $1(50)$ & 0.25 & 0.42 & 0.2 & $3 \cdot 4$ \\
\hline Photo/EBR & 1 & $5 \cdot 3$ & 0 & & & & & \\
\hline None & 1 & $5 \cdot 6$ & 0 & & & & & \\
\hline
\end{tabular}

$\star \mathrm{EBR}=$ External beam radiation; Cryo=cryotherapy; Photo=photocoagulation; En/Enuc=enucleation; Ch/Chemo=chemotherapy. 


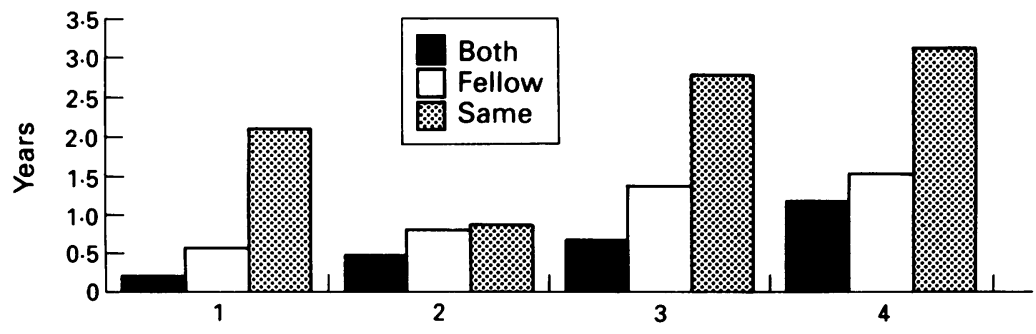

Figure 3 The differences in (1) mean age at diagnosis, (2) mean time interval for development of new tumours, (3) mean age at new tumour diagnosis, and (4) mean age at last diagnosis of new tumours for patients who developed new foci in the same, fellow, or both eyes.
As with the bilateral patients, the risk of developing new tumours after treatment is related to the initial age at diagnosis. The risk in the first 3 months of life being the highest (33\%), lower between 3 and 6 months (15\%), and, with the exception of one patient, the risk drops off to less than $10 \%$ after 6 months of age. These results were similar to the bilateral population, where the highest risk was in the first 3 months (58\%), lower between 3 and 6 months (39\%), and dropped off thereafter - although the relative risk remained at a higher baseline rate of $15-24 \% .^{12}$ Note, however, that the sample population for the bilateral patients in any particular age group was much larger. Overall, the risk among unilateral patients diagnosed within the first year of life was $15 \%$ and less than $3 \%$ for those diagnosed after 1 year of age. Only one new tumour was seen among patients initially diagnosed after 3.5 years of age.

Most new tumours developed between 0.08 to $2 \cdot 83$ years after the initial diagnosis, with a mean time interval of 0.74 years. The latest age for the diagnosis of new tumours ranged from 0.25 to $7 \cdot 50$ years and did not appear to be related to age at diagnosis. The mean age at last diagnosis for all patients was 1.82 years. The bilateral patients had a similar peak age at last diagnosis of 6.25 years, with a maximum time interval of 4.5 years after initial diagnosis for the development of new tumours. $^{12}$

While Table 1 revealed similar data for each treatment modality, the authors did not feel that treatment type could be correlated to the development of new tumours, since choice of treatment may be subject to large bias over the years and the sample populations were not sufficiently large to afford such analysis. It is interesting to note, however, that none of the patients receiving chemotherapy went on to develop new tumours.

Of special interest in the study was the subgroup of patients with a family history of retinoblastoma. While only $35 \%$ of these patients developed new tumour foci, $100 \%$ of the patients who develop new tumours were initially diagnosed within the first 6 months of life. No new tumours were seen in this subgroup after 2.08 years of age. The risk of developing new tumours in this group was lower than for the new tumour population as a whole. The risk of developing new tumours is $20 \%$ for those first diagnosed with retinoblastoma by 3 months of age and $8 \%$ for those first diagnosed between 3 and 6 months of age.

What factors, then, can we use to predict who will and will not develop new tumours? Age at diagnosis is the best predictor of the potential for developing new tumour foci. Overall, $90 \%$ of patients develop retinoblastoma within the first 5 years of life. ${ }^{13-15}$ For both unilateral and bilateral patients, an initial diagnosis of retinoblastoma within the first 6 months of life places the patient at the highest risk of developing new intraocular tumour foci. Likewise, the majority of patients who will develop new tumours will be initially diagnosed before the age of 2 years. Their new lesions will, on the average, develop within 1 year of their initial diagnosis. Patients who have unilateral disease and a family history of retino-

blastoma will always develop new tumours if they the mean age at diagnosis for unilateral patients developing new tumours, 1.0 year, as opposed to those who do not develop new tumours at all, 2.0 years. 
are initially diagnosed before 6 months; and they will most likely develop these new tumours by 2 years of age.

Based upon this information, how can we best assure early detection and treatment of new tumour foci? Current recommendations include examination under anaesthesia every 4 months until the age 3 , every 6 months until age 5 years of age, and without anaesthesia yearly after 5 years of age. ${ }^{15}$ Yearly examinations after age 5 are important for the detection of secondary, nonocular tumours, such as osteosarcoma. ${ }^{16}$ Our study suggests, however, that more frequent examinations within the first 2 years of life may be warranted in order to detect early new tumours. Even though the yield of such examinations may be low, the odds are that patients with unilateral disease and a positive family history are most likely to develop new lesions before the age of 2. Similarly, the mean age at last diagnosis of new tumours overall was only 1.8 years, making the first 2 years of life a more reasonable target for more frequent examinations and early intervention. Since attention must be given to locations anterior and posterior to the equator, and to both the same and fellow eye (especially among those initially diagnosed with retinoblastoma during the first 6 months of life), anaesthesia is necessary.

In contrast, if a unilateral patient with a family history is diagnosed within the first 6 months of life, new tumours usually do not appear after 2.08 years of life. More frequent examinations, therefore, may be indicated under anaesthesia during the first 2 years of life. If a unilateral patient with a family history is diagnosed after 6 months of age, since the risk for new tumour development is low (almost 0\%), examinations may be less frequent and without anaesthesia.

While intraocular location of new tumours varied with treatment, $79 \%$ of new tumours in previously irradiated eyes occurred anterior to the equator (similar to other studies which have found up to $90 \%$ anterior to the equator). ${ }^{17}{ }^{18}$ The fact that no new tumours ever developed in the macula of either eye regardless of treatment modality may influence the clinical decision to treat or not to treat. For example, if one macula is involved at diagnosis, the likelihood of having a fellow macula free of disease is $100 \%$. As a result, plans for treating the fellow eye must be made by considering both the ocular complications and effects on visual acuity and visual fields. Furthermore, if a unilateral patient at diagnosis does not have macular involvement, maximal attempts to treat the eye without enucleation may be considered. This is assuming, of course, that the suspicion for optic nerve involvement is low. ${ }^{19} \mathrm{~A}$ special situation is the patient with a known germinal mutation, in whom avoiding radiation treatment may be beneficial in order to minimise risks for osteosarcoma later on in life.$^{16}$ In such an instance, one must weigh the risks and benefits in deciding if enucleation may be the better option for initial treatment.

1 Abramson DH. The diagnosis of retinoblastoma. Bull $N Y$ Acad Med 1988; 64: 283-317.

2 Ellsworth RM, Boxrud CA. Retinoblastoma. In: Tasman W, Jaeger EA, eds. Duane's clinical ophthalmology. Philadelphia: Jaeger EA, eds. Duane's clinical ophthalm.
Harper \& Row, 1991: Vol 3; chapter 35.

3 Abramson DH, Notterman RB, Ellsworth RM, Kitchin FD. Retinoblastoma treated in infants in the first six months of life. Arch Ophthalmol 1983; 101: 1362-6.

4 Abramson DH, Ellsworth RM, Grumbach N, Kitchin FD. Retinoblastoma: survival, age at detection, and comparison 1914-1958, 1958-1983. F Pediatr Ophthalmol Strabismus 1985; 22: 246-50.

5 Abramson DH. Retinoblastoma: diagnosis and management. Cancer F Clin 1982; 32: 130-40.

6 Abramson DH. Treatment of retinoblastoma. In: Blodi FC, ed. Retinoblastoma (contemporary issues in ophthalmology). ed. Retinoblastoma (contemporary issues in opht

7 Abramson DH, Ellsworth RM, Grumbach N, Buckhout LS, Haik BG. Retinoblastoma: correlation between age at diagnosis and survival. $\mathcal{F}$ Pediatr Ophthalmol Strabismus 1986; 23 : $174-7$

8 Abramson DH, Fusco Marks R, Ellsworth RM, Tretter P, Kitchin ED. The management of unilateral retinoblastoma without primary enucleation. Arch Ophthalmol 1982;100: 1249-52.

9 Rubenfeld M, Abramson DH, Ellsworth RM, Kitchin FD. Unilateral vs bilateral retinoblastoma: correlations between age at diagnosis and stage of ocular disease. Ophthalmology 1986; 93: 1016-9.

10 Abramson $\mathrm{DH}$. The focal treatment of retinoblastoma with emphasis on xenon arc photocoagulation. Acta Ophthalmol 1989; 67: 7-63.

11 Abramson DH, Gallie BL. Retinoblastoma. Curr Opin Ophthalmol 1992; 3: 302-11.

12 Abramson DH, Greenfield DS, Ellsworth RM. Bilateral retinoblastoma. Ophthalmic Paediatr Genet 1992; 13: 1-7.

13 Gallie BL, Dunn JM, Chan H, Hamel PA, Phillips RA. The genetics of retinoblastoma: relevance to the patient. Pediatr Clin North America 1991; 38: 299-314.

14 Shields CL, Shields JA, Shah P. Retinoblastoma in older children. Ophthalmology 1991; 98: 395-9.

15 Shields JA. Retinoblastoma. In: Diagnosis and management of intraocular tumors. St Louis: Mosby, 1983; 437-96.

16 Abramson DH, Ellsworth RM, Kitchin FD, Tung G. Second nonocular tumors in retinoblastoma survivors: are they radiation-induced? Ophthalmology 1984; 91: 1351-5.

17 Salmonsen PC, Ellsworth RM, Kitchin FD. The occurrence of new retinoblastomas after treatment. Trans Am Acad Ophthalmol Otolaryngol 1979; 86: 837-40.

18 Ehlers N, Kaae S. Effects of ionizing radiation on retinoblastoma and on the normal ocular fundus in infants. Acta Ophthalmol 1987; 181 (suppl): 9-84.

19 Jacobiec FA, Rootman J, Jones IS. Secondary and metastatic tumors of the orbit. In: Tasman W, Jaeger EA, eds. Duane's tumors of the orbit. In: Tasman W, Jaeger EA, eds. Duane's
clinical ophthalmology. Philadelphia: Harper \& Row, 1991: Vol 2; chapter 46. 